\title{
Prediabetes Screening and Treatment in Diabetes Prevention: The Impact of Physician Attitudes
}

\author{
Arch G. Mainous III, PhD, Rebecca J. Tanner, MA, Christopher B. Scuderi, DO, \\ Maribeth Porter, MD, and Peter J. Carek, MD
}

Purpose: Detection and treatment of prediabetes is an effective strategy in diabetes prevention. However, most patients with prediabetes are not identified. Our objective was to evaluate the relationship between attitudes toward prediabetes as a clinical construct and screening/treatment behaviors for diabetes prevention among US family physicians.

Methods: An electronic survey of a national sample of academic family physicians (n 1248) was conducted in 2016. Attitude toward prediabetes was calculated using a summated scale assessing agreement with statements regarding prediabetes as a clinical construct. Perceived barriers to diabetes prevention, current strategies for diabetes prevention, and perceptions of peers were also examined.

Results: Physicians who have a positive attitude toward prediabetes as a clinical construct are more likely to follow national guidelines for screening $(58.4 \%$ vs $44.4 ; P<.0001)$ and recommend metformin to their patients for prediabetes $(36.4 \%$ vs $20.9 \% ; P<.0001)$. Physicians perceived a number of barriers to treatment, including a patient's economic resources (71.9\%), sustaining patient motivation (83.2\%), a patient's ability to modify his or her lifestyle (75.3\%), and time to educate patient $(\mathbf{7 5 . 3 \% )}$ as barriers to diabetes prevention.

Conclusions: How physicians view prediabetes varies significantly, and this variation is related to treatment/screening behaviors for diabetes prevention. (J Am Board Fam Med 2016;29:663-671.)

Keywords: Attitude; Behavior Therapy; Life Style; Metformin; Motivation; Physicians, Family; Prediabetic State; Surveys and Questionnaires

Prediabetes is a state that imparts a high risk for developing diabetes. ${ }^{1-4}$ Recent data have shown that more than a third of adults in developed countries have prediabetes. ${ }^{5-7}$ Detection of prediabetes is a fundamental strategy to keep people from transitioning to diabetes. ${ }^{1,3,8}$ Once de-

This article was externally peer reviewed.

Submitted 29 April 2016; revised 13 July 2016; accepted 18 July 2016.

From the Departments of Health Services Research, Management, and Policy (AGM, RJT) and Community Health and Family Medicine (AGM, MP, PJC), University of Florida, Gainesville; and the Department of Community Health and Family Medicine, University of Florida, Jacksonville (CBS).

Funding: none.

Conflict of interest: none declared.

Corresponding author: Arch G. Mainous III, PhD, Department of Health Services Research, Management and Policy, University of Florida Health Sciences Center, PO Box 100195, Gainesville, FL 32610 (E-mail: arch.mainous@ phhp.ufl.edu). tected, prediabetes should be acknowledged with a treatment plan (metformin or intense lifestyle intervention) to prevent or slow the transition to diabetes. ${ }^{2,9}$

Recent estimates suggest that the prevalence of prediabetes among the US adult population is $36 \%$. Even though recommendations and other evidence suggest that detection and treatment of prediabetes is necessary, epidemiologic studies indicate that the vast majority of people with prediabetes are unaware that they have the condition. ${ }^{10}$ Moreover, national estimates of ambulatory care indicate that even with current laboratory tests indicating hemoglobin A1c levels consistent with prediabetes (found in $34 \%$ of visits), adults have a very low likelihood of being diagnosed with prediabetes and this diagnosis noted in the medical record. ${ }^{11}$ Treatment (lifestyle modification counseling and/or metformin) was indicated in the medical record in $23.0 \%$ of those with diagnosed or undiagnosed prediabetes. $^{11}$ 
Given the evidence that prediabetes is underdiagnosed and treated, it is important to understand primary care physicians' apparent reluctance to screen for and manage prediabetes. It has been suggested that identifying and labeling patients as having a "predisease," in particular prediabetes, is overdiagnosis. ${ }^{12,13}$ We sought to use a set of potential attitudes as a discriminator for practice patterns regarding prediabetes. Understanding why prediabetes is not acknowledged and why treatment plans are infrequently provided is critical for successful interventions to improve diabetes prevention. Thus, the purpose of this study was to survey a national sample of family physicians who are members of family medicine academic organizations.

\section{Methods}

This study analyzed a survey conducted as part of the Council of Academic Family Medicine (CAFM) Educational Research Alliance (CERA). CERA is a joint initiative of all 4 major US academic family medicine organizations (the Society of Teachers of Family Medicine, the North American Primary Care Research Group, the Association of Departments of Family Medicine, and the Association of Family Medicine Residency Directors).

The investigators submitted questions related to diabetes prevention for inclusion in the CERA survey. The survey was designed as an omnibus survey incorporating several distinct subprojects focusing on different topic areas. Practicing physician members of CERA-affiliated organizations in the United States were identified for participation. Although these organizations are all headquartered in the United States, some members are from outside the United States. This survey was limited to USbased members. Since some individuals were members of multiple organizations, unique individuals were selected for the sampling frame. The study was approved by the American Academy of Family Physicians Institutional Review Board.

The survey was conducted electronically between February and March 2016, using the infrastructure of the Society of Teachers of Family Medicine. The potential respondents were sent an initial E-mail inviting them to participate. The Email included a personalized greeting, a letter signed by the presidents of each of the 4 participating organizations urging participation, and a link to the survey. Nonrespondents were sent 2 follow-up E-mails encouraging participation.

The survey was sent to 3750 physicians who are members of CAFM organizations. Excluding those who were ineligible or undeliverable resulted in a potential sample of 3602 . The survey received 1248 responses, for an overall response rate of $34.65 \%$. Because the survey was structured as an omibus survey, with several subprojects contained within the overall survey, individuals had the option of skipping individual questions or sections of the questionnaire. Thus the sample size for different sections of the questionnaire may vary from the overall sample size of 1248 respondents.

The survey questions for this study were developed following a review of the literature to identify key concepts and issues suggesting the need for additional knowledge. ${ }^{2,8,11-13}$ We evaluated demographics and current diabetes prevention practices. The attitudinal outcomes of interest were physicians' responses to questions related to their attitudes toward diabetes prevention and perceived barriers to diabetes prevention.

\section{Attitudes Toward Prediabetes}

We assessed agreement on 8 items about prediabetes using a 5-point Likert-type scale (1, strongly disagree, to 5, strongly agree). These items focused on issues such as the strength of the current evidence for prediabetes screening and treatment, costs and benefits of formally diagnosing patients with prediabetes, and value in focusing on prediabetes for diabetes prevention. We reverse-coded the 3 items for which an answer of disagree would indicate more positive attitudes toward the concept of prediabetes. We then created a summated index of the 8 items with a higher score representing a more positive attitude toward the concept of prediabetes. We split the index at the median so that a score of $\geq 27$ would indicate a positive attitude toward prediabetes as a diagnostic construct and those $<27$ would have a less positive attitude. The 8 items can be found in Table 1 .

\section{Perceived Barriers to Diabetes Prevention}

We presented 10 possible barriers to diabetes prevention. These were measured on a 5 -point scale (1, not a barrier at all, to 5 , extreme barrier). These potential barriers included (1) medication compliance, (2) patient's acceptance of diabetes diagnosis, (3) insurance coverage for patient education, (4) 
The national guidelines and recommendations for diabetes prevention focused on screening for prediabetes are useful in my practice.

Diabetes prevention should be focused on individuals with lab values indicating abnormal blood glucose consistent with prediabetes.

*Diabetes prevention should be a focus for all patients, regardless of blood glucose levels.

Diagnosing a patient as being prediabetic is an effective way to increase patient awareness of their need for treatment.

*Diagnosing prediabetes is misleading to patients regarding them having a disease.

*Diagnosing a patient with prediabetes risks overtreatment.

Current evidence supports the utility of screening for prediabetes.

Current evidence supports the effectiveness of treating prediabetes.

Each item was answered using a 5-point scale (1, strongly disagree, to 5, strongly agree).

*Items were reverse coded so that on the summated index, a higher score on the index represented a more positive attitude toward the construct of prediabetes.

patient's ability to modify his or her lifestyle, (5) time needed to educate patient on diet and lifestyle, (6) insurance coverage for glucometers, (7) patient's economic resources, (8) sustaining patient motivation, (9) time for follow-up with patient, and (10) knowledge of treatment options for prediabetes.

\section{Attitudes Toward Treatment}

We examined several attitudes toward treatment, including the respondent's belief in his or her ability to implement lifestyle management for patients and patients' ability to comply.

\section{Current Strategies for Diabetes Prevention}

We evaluated the reported physician behaviors in terms of providing lifestyle advice to patients with prediabetes by asking about the primary change that they stress to patients (eg, diet, exercise, weight loss). We also evaluated whether the respondent gives general lifestyle advice targeted toward reducing cardiovascular disease instead of advice specific to diabetes to patients with abnormal blood glucose. In addition, respondents were asked the primary strategy for identifying patients at high risk for developing diabetes and which guideline they follow, if any, for diabetes prevention. Table 2 shows the guidelines for screening for prediabetes from the American Diabetes Association and the US Preventive Services Task Force (USPSTF). Metformin as a strategy was also assessed.

\section{Perceptions of Peers and Prediabetes}

We asked the respondents to indicate their agreement (1, strongly disagree; 5 , strongly agree) with the statement, "Most family physicians do not consider screening for prediabetes to be a high priority in diabetes prevention."

\section{Demographics}

We collected data on age, race/ethnicity, academic rank, time in clinic, proportion of patients with diabetes, and proportion of patient population with glucose concentrations consistent with prediabetes.

\section{Analysis}

We examined demographic and practice characteristics for the full sample. We calculated the bivariate relationship between positivity of attitude regarding the utility of prediabetes as a diagnostic

Table 2. Current Guidelines for Screening for Abnormal Blood Glucose

\begin{tabular}{lc}
\hline Guideline Source & Guideline \\
\hline $\begin{array}{l}\text { American Diabetes } \\
\text { Association }\end{array}$ & $\begin{array}{c}\text { Testing to assess risk for future diabetes in asymptomatic people should be considered in adults } \\
\text { of any age who are overweight or obese }\left(\mathrm{BMI} \geq 25 \mathrm{~kg} / \mathrm{m}^{2} \text { or } \geq 23 \mathrm{~kg} / \mathrm{m}^{2} \text { in Asian Americans) }\right. \\
\text { and who have } \geq 1 \text { additional risk factor for diabetes. For all patients, testing should begin at } \\
\text { age } 45 \text { years. }{ }^{1}\end{array}$ \\
$\begin{array}{c}\text { Screening for abnormal blood glucose is recommended as part of cardiovascular risk assessment } \\
\text { in adults aged } 40 \text { to } 70 \text { years who are overweight or obese. }{ }^{14}\end{array}$ \\
\begin{tabular}{l} 
Force \\
\hline
\end{tabular}
\end{tabular}

BMI, body mass index. 
construct and variables assessing current practice, attitudes toward treatment of prediabetes, and assessment of peers. We also calculated the bivariate relationship between demographic characteristics and the positivity of attitudes regarding prediabetes as a diagnosis.

\section{Results}

The characteristics of the respondents are shown in Table 3 . Nearly half spend $<3$ half days a week in patient care, and $30 \%$ have been in practice $\leq 10$ years. Table 3 also shows the bivariate relationships between attitude toward prediabetes and demographic characteristics. Female physicians and younger physicians have a more positive attitude toward prediabetes as a diagnostic construct. Minority physicians and physicians who have been practicing fewer years also have a more positive attitude toward prediabetes as a clinical construct.

Table 4 shows the sampled physicians' screening and treatment patterns. Rather than focusing on 1 behavioral change, a majority of sampled physicians reported stressing equally dietary change, weight loss, and increased leisure time physical activity. The majority indicated using blood glucose testing as their primary method for screening patients for prediabetes, followed by assessing body mass index. Only $52.4 \%$ of respondents reported actually following national guidelines; another third was uncertain whether the screening and care they provided were consistent with guidelines. We checked the validity of screening behaviors, specifically regarding the USPSTF guidelines. Despite the new, final guidelines being in place for 4 months at the time the survey was in the field, $2.0 \%$ of physicians reported using the draft guidelines, compared with $35.4 \%$ who indicated they used the current guidelines.

Table 4 also presents the bivariate relationships between the positivity of a physician's view of prediabetes as a clinical construct and attitudes regarding treatment, current practice, and assessment of peers. Physicians with a positive attitude toward prediabetes more frequently provide less general lifestyle advice; they disagree that patients cannot successfully comply with lifestyle changes needed for diabetes prevention, recommend metformin to patients with prediabetes, and follow national guidelines. In addition, physicians with a positive attitude toward prediabetes more frequently use the American Diabetes Association (ADA) as their primary guideline, whereas physicians with a less positive attitude indicate that they use the current USPSTF guidelines.

Table 5 presents the bivariate relationships between physician attitude and perceived barriers to diabetes prevention. The severity of perceived barriers differed between the 2 physician groups on a number of items. Notably, a large majority of physicians-both those with positive and those with negative attitudes toward prediabetes-believe a patient's ability to modify lifestyle, economic resources, time for patient education on lifestyle modification, and sustaining patient motivation are significant barriers to prediabetes care.

In addition to splitting physician attitudes at a median score of 27 , we also conducted analyses comparing the highest and lowest quartiles. Scores $\leq 25$ were in the lowest quartile, whereas scores $\geq 30$ were in the highest quartile. The results remained consistent with the results using a median split.

\section{Discussion}

The results of this study of academic family physicians reinforce that diabetes prevention is an important issue in clinical practice. However, the strategy of achieving diabetes prevention through screening for and treating patients with prediabetes is not universally embraced by academic family physicians in the United States. Importantly, respondents who had a more negative set of attitudes toward prediabetes were less likely to believe that patients can successfully follow lifestyle changes needed for diabetes prevention, were less likely to recommend metformin to patients with prediabetes, and were less likely to agree that screening for prediabetes is a high priority for family physicians. They were also more likely to recommend a general lifestyle aimed at reducing cardiovascular disease, potentially encompassing a concept like the metabolic syndrome, rather than advice tailored toward lowering blood glucose concentrations.

Adherence to guidelines regarding the screening for and treating prediabetes for diabetes prevention was a key component of this study. For several years, 2 major organizations, the ADA and the USPSTF, had inconsistent recommendations for diabetes and prediabetes screening. ${ }^{14,15}$ In 2008 the USPSTF revised its guidelines to recommend 
Table 3. Characteristics of the Respondents $(n=1248)$

\begin{tabular}{|c|c|c|c|c|}
\hline & Total & $\begin{array}{c}\text { Positive Attitude Toward } \\
\text { Prediabetes }\end{array}$ & $\begin{array}{c}\text { Less Positive Attitude Toward } \\
\text { Prediabetes }\end{array}$ & $P$ Value \\
\hline Sex & & & & $<.0001$ \\
\hline Male & 50.4 & 44.8 & 57.5 & \\
\hline Female & 49.6 & 55.2 & 42.5 & \\
\hline Age (years) & & & & .003 \\
\hline $20-29$ & 0.3 & 27.4 & 19.5 & \\
\hline $30-39$ & 24.2 & 32 & 30.2 & \\
\hline $40-49$ & 30.9 & 24.3 & 27.8 & \\
\hline $50-59$ & 25.3 & 16.3 & 22.5 & \\
\hline$\geq 60$ & 19.3 & & & \\
\hline Race & & & & .04 \\
\hline Hispanic & 4.4 & 5.1 & 3.2 & \\
\hline Non-Hispanic white & 81.8 & 79.9 & 86.5 & \\
\hline Non-Hispanic black & 4.4 & 4.6 & 3 & \\
\hline Asian/other & 9.4 & 10.5 & 7.3 & \\
\hline Rank & & & & .002 \\
\hline Assistant professor & 38.4 & 42.8 & 33.0 & \\
\hline Associate professor & 30.2 & 29.6 & 30.6 & \\
\hline Full professor & 20.2 & 16.7 & 25.1 & \\
\hline Visiting professor & 0.2 & 0.2 & 0.2 & \\
\hline Not applicable & 11 & 10.8 & 11.1 & \\
\hline Terminal Degree & & & & .008 \\
\hline MD & 90.7 & 89.4 & 93.5 & \\
\hline DO & 8.9 & 10.6 & 6.1 & \\
\hline Other & 0.4 & 0 & 0.4 & \\
\hline Half days in the clinic (n) & & & & .54 \\
\hline$<3$ & 49.4 & 47.7 & 50.2 & \\
\hline 3 to 6 & 45.3 & 46.6 & 45.3 & \\
\hline$\geq 7$ & 5.3 & 5.7 & 4.5 & \\
\hline Years in practice & & & & .003 \\
\hline $1-10$ & 29.6 & 32.2 & 25.2 & \\
\hline $11-20$ & 31.4 & 33.3 & 29.6 & \\
\hline $21-30$ & 23.1 & 21 & 26.2 & \\
\hline$>30$ & 15.9 & 13.5 & 19 & \\
\hline Proportion of patients with diabetes & & & & .04 \\
\hline$<10 \%$ & 11.1 & 11.2 & 10.9 & \\
\hline $10-24 \%$ & 55.1 & 52.5 & 59.6 & \\
\hline $25-49 \%$ & 29.8 & 31.2 & 27 & \\
\hline$\geq 50 \%$ & 4.0 & 5.1 & 2.5 & \\
\hline Proportion of patients with prediabetes & & & & .06 \\
\hline$<10 \%$ & 21.5 & 20.5 & 22.6 & \\
\hline $10-24 \%$ & 58.9 & 57.6 & 61.4 & \\
\hline $25-49 \%$ & 17.4 & 19 & 14.7 & \\
\hline$\geq 50 \%$ & 2.2 & 2.9 & 1.3 & \\
\hline \multicolumn{5}{|l|}{ Attitudes toward prediabetes } \\
\hline Range & $13-37$ & & & \\
\hline Median & 27 & & & \\
\hline
\end{tabular}

Data are percentages unless otherwise indicated. 
Table 4. Practice Patterns and Treatment Attitudes by Attitude about Prediabetes

\begin{tabular}{|c|c|c|c|c|}
\hline & Total & $\begin{array}{l}\text { Positive Attitude Toward } \\
\text { Prediabetes }\end{array}$ & $\begin{array}{l}\text { Less Positive Attitude } \\
\text { Toward Prediabetes }\end{array}$ & $P$ Value \\
\hline $\begin{array}{l}\text { Most family physicians do not consider screening } \\
\text { for prediabetes to be a high priority in } \\
\text { diabetes prevention. }\end{array}$ & & & & $<.0001$ \\
\hline Disagree/strongly disagree & 56.1 & 67.5 & 40.3 & \\
\hline Neutral & 26.7 & 21.1 & 34.7 & \\
\hline Agree/strongly agree & 17.2 & 11.4 & 25 & \\
\hline $\begin{array}{l}\text { I give general lifestyle advice targeted toward } \\
\text { reducing cardiovascular disease instead of } \\
\text { advice specific to diabetes to patients with } \\
\text { abnormal blood glucose. }\end{array}$ & & & & $<.0001$ \\
\hline Disagree/strongly disagree & 45.4 & 53.2 & 35.1 & \\
\hline Neutral & 17.0 & 17 & 17.6 & \\
\hline Agree/strongly agree & 37.6 & 29.8 & 47.4 & \\
\hline $\begin{array}{l}\text { Most patients cannot successfully comply with } \\
\text { lifestyle changes needed for diabetes } \\
\text { prevention. }\end{array}$ & & & & .0002 \\
\hline Disagree/strongly disagree & 46.6 & 52.2 & 39.5 & \\
\hline Neutral & 23.1 & 20.7 & 26.2 & \\
\hline Agree/strongly agree & 30.4 & 27.1 & 34.3 & \\
\hline $\begin{array}{l}\text { I recommend metformin to most patients with } \\
\text { prediabetes. }\end{array}$ & & & & $<.0001$ \\
\hline Disagree/strongly disagree & 42.9 & 36.5 & 52.4 & $<.0001$ \\
\hline Neutral & 27.1 & 27.1 & 26.6 & \\
\hline Agree/strongly agree & 30.0 & 36.4 & 20.9 & \\
\hline Primary lifestyle change stressed & & & & .01 \\
\hline Changing diet & 20.7 & 21.2 & 19.1 & \\
\hline Increasing leisure time physical activity & 10.0 & 7.5 & 13.6 & \\
\hline Weight loss & 11.3 & 11.7 & 10.4 & \\
\hline Stress all 3 equally & 58.0 & 59.6 & 57 & \\
\hline $\begin{array}{l}\text { Primary method of identifying someone at risk } \\
\text { of developing diabetes }\end{array}$ & & & & .11 \\
\hline Assessing BMI & 38.7 & 36.4 & 41.8 & \\
\hline Testing blood glucose concentrations & 52.1 & 55.3 & 48 & \\
\hline Asking about family history & 8.0 & 7.2 & 8.7 & \\
\hline Other & 1.2 & 1.1 & 1.5 & \\
\hline $\begin{array}{l}\text { Follow national guideline or screening } \\
\text { recommendation }\end{array}$ & & & & $<.0001$ \\
\hline Yes & 52.4 & 58.4 & 44.4 & \\
\hline No & 18.1 & 15 & 21.9 & \\
\hline Don't know & 29.5 & 26.5 & 33.8 & \\
\hline Primary guideline followed & & & & .0001 \\
\hline American Diabetes Association & 25.2 & 31 & 15.3 & \\
\hline USPSTF current guidelines & 35.5 & 31.8 & 43.5 & \\
\hline USPSTF draft guidelines & 2.0 & 1.3 & 3.4 & \\
\hline Other/combination of guidelines & 36.5 & 35.2 & 37.8 & \\
\hline Don't know & 0.8 & 0.8 & 0 & \\
\hline
\end{tabular}

Data are percentages unless otherwise indicated.

BMI, body mass index; USPSTF, US Preventive Services Task Force.

that only asymptomatic adults with sustained blood pressure $>135 / 80 \mathrm{mmHg}$ be screened for type 2 diabetes and no recommendation for screening for prediabetes. $^{14}$ Several studies showed that, in comparison to the ADA recommendations, the USPSTF recommendations re- 
Table 5. Perceived Barriers to Diabetes Prevention by Attitude Toward Prediabetes

\begin{tabular}{|c|c|c|c|c|}
\hline Perceived Barriers to Diabetes Prevention & Total & $\begin{array}{l}\text { Positive Attitude Toward } \\
\text { Prediabetes }\end{array}$ & $\begin{array}{c}\text { Less Positive Attitude Toward } \\
\text { Prediabetes }\end{array}$ & $P$ Value \\
\hline Medication compliance & & & & .0002 \\
\hline Not a barrier/somewhat of a barrier & 41.1 & 43.8 & 37.7 & \\
\hline Neutral & 19.5 & 15.3 & 25.1 & \\
\hline A barrier/extreme barrier & 39.4 & 41 & 37.2 & \\
\hline Patient acceptance of prediabetes diagnosis & & & & .0001 \\
\hline Not a barrier/somewhat of a barrier & 46.0 & 50.6 & 39.5 & \\
\hline Neutral & 24.1 & 20 & 29.7 & \\
\hline A barrier/extreme barrier & 29.9 & 29.4 & 30.8 & \\
\hline Insurance coverage of education for patient & & & & .09 \\
\hline Not a barrier/somewhat of a barrier & 31.8 & 34.6 & 29 & \\
\hline Neutral & 15.9 & 14.3 & 17.8 & \\
\hline A barrier/extreme barrier & 52.3 & 51.1 & 53.2 & \\
\hline Patient ability to modify lifestyle & & & & .19 \\
\hline Not a barrier/somewhat of a barrier & 15.0 & 16.8 & 13 & \\
\hline Neutral & 5.5 & 5 & 5.8 & \\
\hline A barrier/extreme barrier & 79.5 & 78.2 & 81.2 & \\
\hline $\begin{array}{l}\text { Time needed to educate patient on diet and } \\
\text { lifestyle change }\end{array}$ & & & & .03 \\
\hline Not a barrier/somewhat of a barrier & 16.4 & 19.2 & 13.2 & \\
\hline Neutral & 8.3 & 7.6 & 8.9 & \\
\hline A barrier/extreme barrier & 75.3 & 73.2 & 78 & \\
\hline Insurance coverage for glucometers for patients & & & & .22 \\
\hline Not a barrier/somewhat of a barrier & 45.2 & 46.8 & 43.6 & \\
\hline Neutral & 21.5 & 19.3 & 23.5 & \\
\hline A barrier/extreme barrier & 33.4 & 33.9 & 32.8 & \\
\hline Economic resources of patients & & & & .3 \\
\hline Not a barrier/somewhat of a barrier & 21.4 & 23.1 & 19.9 & \\
\hline Neutral & 6.7 & 5.9 & 7.6 & \\
\hline A barrier/extreme barrier & 71.9 & 71 & 72.5 & \\
\hline Sustaining patient motivation & & & & .25 \\
\hline Not a barrier/somewhat of a barrier & 11.6 & 13 & 10.4 & \\
\hline Neutral & 5.2 & 5.4 & 4.3 & \\
\hline A barrier/extreme barrier & 83.2 & 81.5 & 85.3 & \\
\hline Time for patient follow-up & & & & .06 \\
\hline Not a barrier/somewhat of a barrier & 26.3 & 29.1 & 23.2 & \\
\hline Neutral & 18.1 & 18 & 17.3 & \\
\hline A barrier/extreme barrier & 55.6 & 52.9 & 59.5 & \\
\hline Not a barrier/somewhat of a barrier & & & & .06 \\
\hline Neutral & 65.5 & 68.4 & 62 & \\
\hline A barrier/extreme barrier & 23.8 & 22.4 & 25.5 & \\
\hline A barrier/extreme barrier & 10.6 & 9.2 & 12.5 & \\
\hline
\end{tabular}

Data are percentages unless otherwise indicated.

sulted in many cases of undiagnosed diabetes being missed, and did not provide direction on diabetes prevention via prediabetes. ${ }^{16,17}$ In October 2015, 4 months before data collection for this survey, the USPSTF revised its guidelines to recommend screening for prediabetes, thereby having both the
ADA and the USPSTF recommending screening for prediabetes. ${ }^{3}$

The results of this study showed that respondents who were less positive in their attitudes toward prediabetes were less likely to say that they followed national guidelines on diabetes 
prevention. It is possible that those who were less positive about prediabetes may have been more oriented toward the approach of the USPSTF. However, that is unclear from our data because although there was no draft recommendation from the USPSTF, some of the respondents said that was the guideline they followed. Consequently, we do not know whether individuals were confused about the change in the USPSTF recommendation and reported following the old USPSTF recommendation or the current recommendation. Since the revised guidelines were published only 4 months before this survey, it is possible that many family physicians surveyed were not familiar with the new guidelines.

Several key barriers were identified, including a variety of patient-level constraints including sustaining patients' motivation for lifestyle change and patients' ability to change their lifestyle. These barriers make future interventions for diabetes prevention even more difficult. Focusing on an interdisciplinary team approach with appropriate financing may be necessary to successfully address diabetes prevention in primary care. The Diabetes Prevention Program demonstrated the success of rigorous lifestyle change and metformin for diabetes prevention. ${ }^{18}$ Yet the Diabetes Prevention Program must function a resource that can work cooperatively with primary care physicians.

To our knowledge, this study is the first to focus on attitudes toward prediabetes among a national sample of family physicians and how those attitudes may affect diabetes prevention. In addition to this strength, there are several limitations to the generalizability of these results. First, respondents are from all in academic settings. Although academic physicians should be a group particularly in touch with new knowledge because of their role in teaching and research, the vast majority do not have full-time clinical practices. ${ }^{19}$ Thus the results of this study cannot be generalized to all family physicians, particularly those in private practice. Second, even though the sample size allows us to examine responses from $>1200$ respondents, the response rate of $35 \%$ is not exceptionally high. Thus there may be some bias among the participants based on their interest in the questions. Although all potential respondents are members of CAFM organizations, it is possible that some of the individuals do not strongly identify with the organizations and thus did not participate. Finally, we were unable to validate the actual practice of the respondents in relation to their responses. It is unclear how well the physicians' actual clinical practice corresponds to their perceptions of their clinical practice. The inability to relate physician perceptions of practice to their actual practice is a significant limitation of this study. However, the questions primarily focused on perceptions about barriers to care and attitudes toward strategies for diabetes prevention, rather than attempting to quantify actual practice behaviors.

\section{Conclusion}

There seems to be a great deal of variation in how family physicians view prediabetes as a strategy for diabetes prevention. Only slightly more than half of physicians surveyed reported following national guidelines for diabetes prevention, and a variety of guidelines are followed. In addition, physicians perceive significant barriers to diabetes prevention. To improve diabetes prevention in academic family medicine, a multifaceted approach that targets physician understanding and compliance with guidelines as well as interventions to diminish patient barriers to diabetes prevention are necessary.

\section{References}

1. American Diabetes Association. Diagnosis and classification of diabetes mellitus. Diabetes Care 2016; 39(Suppl 1):S13-22.

2. American Diabetes Association. Prevention or delay of type 2 diabetes. Diabetes Care 2015;38(Suppl 1): S31-2.

3. U.S. Preventive Services Task Force. Abnormal blood glucose and type 2 diabetes mellitus: screening. October 2015. Available from: http://www. uspreventiveservicestaskforce.org/Page/Document/ UpdateSummaryFinal/screening-for-abnormalblood-glucose-and-type-2-diabetes. Accessed April 2016.

4. Tabak AG, Herder C, Rathmann W, Brunner EJ, Kivimaki M. Prediabetes: a high-risk state for diabetes development. Lancet 2012;379:2279-90.

5. Bullard KM, Saydah SH, Imperatore G, et al. Secular changes in U.S. prediabetes prevalence defined by hemoglobin A1c and fasting plasma glucose: $\mathrm{Na}-$ tional Health and Nutrition Examination Surveys, 1999-2010. Diabetes Care 2013;36:2286-93.

6. Mainous AG 3rd, Tanner RJ, Baker R, Zayas CE, Harle CA. Prevalence of prediabetes in England from 2003 to 2011: population-based, cross-sectional study. BMJ Open 2014;4:e005002. 
7. Menke A, Casagrande S, Geiss L, Cowie CC. Prevalence of and trends in diabetes among adults in the United States, 1988-2012. JAMA 2015;314:1021-9.

8. Selph S, Dana T, Blazina I, Bougatsos C, Patel H, Chou R. Screening for type 2 diabetes mellitus: a systematic review for the U.S. Preventive Services Task Force. Ann Intern Med 2015;162:765-76.

9. Dunkley AJ, Bodicoat DH, Greaves CJ, et al. Diabetes prevention in the real world: effectiveness of pragmatic lifestyle interventions for the prevention of type 2 diabetes and of the impact of adherence to guideline recommendations: a systematic review and meta-analysis. Diabetes Care 2014;37:922-33.

10. Centers for Disease Control and Prevention (CDC). Awareness of prediabetes-United States, 2005-2010. MMWR Morb Mortal Wkly Rep 2013;62:209-12.

11. Mainous AG 3rd, Tanner RJ, Baker R. Prediabetes diagnosis and treatment in primary care. J Am Board Fam Med 2016;29:283-5.

12. Treadwell J, McCartney M. Overdiagnosis and overtreatment: generalists-it's time for a grassroots revolution. Br J Gen Pract 2016;66:116-7.

13. Yudkin JS, Montori VM. The epidemic of pre-diabetes: the medicine and the politics. BMJ 2014;349: g4485.
14. U.S. Preventive Services Task Force. Screening for type 2 diabetes mellitus in adults: U.S. Preventive Services Task Force recommendation statement. Ann Intern Med 2008;148:846-54.

15. American Diabetes Association. Diagnosis and classification of diabetes mellitus. Diabetes Care 2012;35 (supp 1):S64-S71.

16. Dall TM, Narayan KM, Gillespie KB, et al. Detecting type 2 diabetes and prediabetes among asymptomatic adults in the United States: modeling American Diabetes Association versus US Preventive Services Task Force diabetes screening guidelines. Popul Health Metr 2014;12:12.

17. Casagrande SS, Cowie CC, Fradkin JE. Utility of the U.S. Preventive Services Task Force criteria for diabetes screening. Am J Prev Med 2013;45:167-74.

18. Diabetes Prevention Program Research Group, Knowler WC, Fowler SE, Hamman RF, et al. 10Year follow-up of diabetes incidence and weight loss in the Diabetes Prevention Program Outcomes Study. Lancet 2009;374:1677-86.

19. Lin TL, Williams T, He J, et al. Rates of complete diagnostic testing for patients with acute myeloid leukemia. Cancer Med 2015;4:519-22. 